Medical Research Archives. Volume 5, issue 5. May 2017.

\title{
Polyetheretherketone (PEEK) as a medical and dental material. A literature review
}

Authors

Jordi Ortega-Martínez

Montse Farré-Lladós

Jordi Cano-Batalla

Josep Cabratosa-Termes

\section{Affiliation}

Department of Restorative Dentistry and Endodontics, Universitat Internacional de Catalunya, Barcelona, Spain

\section{Correspondence}

Faculty of Dentistry, Universitat Internacional de Catalunya, Josep Trueta s/n 08195 Sant Cugat del Vallès, Barcelona (Spain), jortega@uic.es

\begin{abstract}
Introduction: Thermoplastic polymers have many potential uses in medicine and dentistry as an alternative to the commonly used titanium. Due to several advantages of these materials, metal-free restorations are performing an important role in current medical therapies. The aim of this review was to evaluate Polyetheretherketone (PEEK) as an alternative material to titanium in medical and dental clinical cases.
\end{abstract}

Methods: Original scientific articles published in Medline-Pubmed database were electronically searched to accomplish the objectives of the study. Only articles published in English were included from 2000 to present using a variety of keywords in combination. The studies relevant to our review were analysed and compared.

Conclusions: The literature suggests that PEEK offers an alternative to titanium, especially in cases of orthopaedics and trauma. Its properties make it an interesting material in oral implantology to be performed with CAD-CAM. Further studies are required to obtain sufficient scientific evidence to enable its uses as a permanent material.

Keywords: Titanium; Biocompatibility; Bioactivity; Polyetheretherketone; Polymers; PEEK; PAEK; HighPerformance Polymer; CFR-PEEK; Dental Implants; Oral Medicine; Orthopaedics 


\section{Polyetheretherketone (PEEK) as a medical and dental material. A literature review}

\section{Introduction}

\subsection{The history of PEEK}

Of the many currently available polymers, such as PTFE, PMMA, PLA, UHMWPE, PGA, only a few are used for bone replacement purposes, because most polymers absorb liquids, swell, leach undesirable products and they can be affected by sterilization. Moreover, some polymers are also too flexible and too weak for use in orthopedic implants [1]. In 1978 a group of English scientists developed PEEK (poly-ether-ether-ketone), a semicrystalline linear polycyclic aromatic thermoplastic. It was first commercialized in the 1980s for industrial applications in the manufacture of aircraft, turbine blades, piston parts, cable insulation, bearings and compressor plate valves, among others [12]. PEEK later became an important alternative for metal implant components, especially in traumatic applications, orthopedics and spinal implants [1-4].

\subsection{Structure and properties of PEEK}

According to Ma et al. PEEK, a member of the polyaryletherketone family (PAEK), has an aromatic molecular backbone, with combinations of ketone and ether functional groups between the aryl rings as show Figure 1 [1].

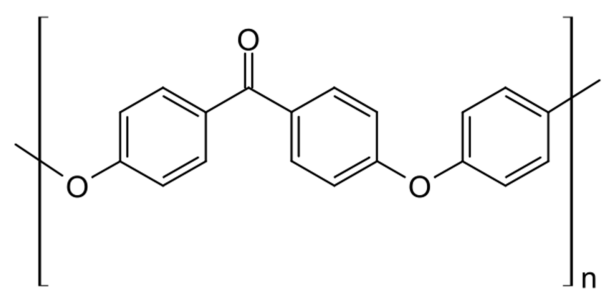

Figure 1: Chemical structure of PEEK

PEEK is a radiolucent material that is chemically and physically stable and resistant to radiation damage. It is also wear-resistant, compatible with many reinforcing agents (such as glass and carbon fibers), stable at temperatures exceeding $300^{\circ} \mathrm{C}$. This polymer is very biocompatible in vivo and in vitro, does not cause toxic or mutagenic effects; therefore it is indicative in patients allergic to titanium [1,4-6]. Notwithstanding, Maldonado-Naranjo et al. described a case report with clinical evidence of allergy to PEEK. The symptoms described were angioedema, itching, swelling of the tongue, and skin thickening following an intervertebral PEEK cage intervention.
Removal of the implant alleviated the patient's allergic symptoms [2]. Nevertheless, the literature has reported only one case, suggesting that tissue reactions to PEEK are extremely rare.

Regarding its mechanical properties, PEEK has an elastic modulus similar to human cortical bone (3-4 GPa), suggesting the potential for a more homogenous stress distribution to the support tissues $[1,3]$.

The inert character of the bone-to-implant contact (BIC) of PEEK needs to be improved. To this end, two strategies are currently being pursued. One involves surface modification (surface treatment alone or in combination with a surface 


\section{Polyetheretherketone (PEEK) as a medical and dental material. A literature review}

coating); and the second consists of composite preparation [1].

\subsection{Surface modification}

PEEK can be modified by two treatments. The first is a chemical treatment, which is rarely used, and only two options are available: wet chemistry modification and sulfonation treatment [1].

In contrast, PEEK can be modified by a large number of physical treatments: plasma modifications (such as nitrogen and oxygen plasma, ammonia/argon plasma, oxygen plasma, methane and oxygen plasma, ammonia plasma, oxygen and argon plasma, and hydrogen/argon plasma) and accelerated neutral atom beam (ANAB) [1].

Plasma modification has long been used to modify PEEK. This modification was found to increase adhesion, proliferation, and osteogenic differentiation.

ANAB has been shown in in vitro experiments to enhance the growth of human fetal osteoblast cells and increase osteointegration [1].

Regarding surface coating, a number of materials have been used such as titanium, gold, titanium dioxide, diamond-like carbon, tert-butoxides, and hydroxyapatite (HA). The last of these is the most widely used material due to its biocompatibility, bioactivity, and osteoconductivity in vivo. Surface coatings can be applied using the following techniques: aerosol deposition, vacuum plasma spraying, arc ion plating, plasma immersion ion implantation and deposition, physical vapor deposition, cold spray technique, electron beam deposition, ionic plasma deposition, radio-frequency magnetron sputtering, and spin coating [1].

\subsection{Composite Preparation}

A good strategy to improve the bioactivity of PEEK is by impregnating it with bioactive materials. Depending on the size of these materials, PEEK composites are classified as conventional PEEK and nanosized $(<100 \mathrm{~nm})$ PEEK composites.

One conventional PEEK composite, known as HA (hydroxyapatite), has good biocompatibility, bioactivity and osteoconduction, and can be used as a filler material to prepare PEEK composites. The increase in the amount of HA content improves tensile modulus and microhardness, but decreases tensile strength and strain to fracture [1].

\subsection{Medical Applications}

The biocompatibility and human bone-like elastic modulus make PEEK a good alternative to metal implant components, especially in orthopedic and traumatic applications. Furthermore, this polymer is used in cardiovascular applications $[1,3,6-$ $8]$.

Carbon fiber reinforced (CFR-PEEK) fixation plates were developed as an alternative to stainless steel bone plates. CFR-PEEK is also used in fracture fixation and femoral prosthesis in artificial hip joints [1,3-4].

PEEK is widely used as a material for the interbody fusion cage in vertebral surgery and spinal applications. It has also been considered for finger joint replacements and total disc replacement [1,3-4].

Orthopedic implants usually include metals, ceramics, composites and polymers. Metals, such as $\mathrm{Ni}-\mathrm{Ti}, \mathrm{Ti}, \mathrm{Co}-\mathrm{Cr}$, are used for permanent and temporary implants, but they have drawbacks. The drawbacks of metal include allergies, a 


\section{Polyetheretherketone (PEEK) as a medical and dental material. A literature review}

high elastic modulus, which can cause stress on the peri-implant bone, and the radiopacity of this metal causes artifacts in CT-Scans [1,3-4].

The drawbacks of ceramics include high elastic modulus, low fracture toughness and ductility [1]. In short, PEEK offers the best biomaterial substitute for metal implants and ceramics.

\subsection{Dental Applications}

Unlike metal, PEEK is biocompatible and has a natural tooth-colored appearance, hence its widespread use in implants, provisional abutments, implant supported bars, or clamp materials in the field of removable dental prostheses and maxillary obturator prostheses [9-11]. PEEK also offers an alternative to orthodontic wires for reasons of improved aesthetics, allergies to metals, and interference of metals with TC [10].

Furthermore, PEEK can be easily shaped with dental burs, although, owing to its low translucency and grayish pigmentation, it still requires veneering [11].

Zoidis et al. described a case in which modified PEEK containing 20\% ceramic fillers (BioHPP) was used, in combination with acrylic resin, the traditional denture base, as an alternative framework material for removable dental prostheses [6].

The biocompatibility, flexural bone modulus, resistance to cracking, ease of polishing, and machinability of PEEKOPTIMA (reinforced poly-ether-etherketone), allows its use as a material in the palatal section of maxillary obturator prostheses in patients with large oral-nasal defects [9].

Lee et al. when evaluating the fatigue limits and the effects of the low elastic modulus of dental implants made with PEEK may reduce the stress shielding effect [12].

\section{Objectives}

The aim of this study was to analyze the history, composition and applications of PEEK in medicine and dentistry.

It also reviewed the characteristics of PEEK (the elastic modulus, the types of surface treatments required) and the types available. The present study also undertook to ascertain whether this polymer is used as a permanent/provisional material in dentistry and medicine.

\section{Methods}

\subsection{Search strategy}

An electronic search of the literature was performed using Medline-Pubmed from 2000 to December 2015. The search strands were designed to investigate which types of PEEK exist; their applications in dentistry and in medicine (focusing more on dentistry); the treatments that are applied on the surface of PEEK, and also to compare titanium and PEEK.

Keywords used to search were titanium, biocompatibility, bioactivity, polyetheretherketone, polymers, PEEK, PAEK, high-performance polymer, CFRPEEK, dental implants, oral medicine, orthopaedics in combination.

\subsection{Eligibility criteria}

No language restrictions were applied and only papers reporting information related to the outcomes of PEEK, used as a material in dentistry, were included. Papers whose full-text versions could not be retrieved and those published before 2000 were excluded. 
Medical Research Archives. Volume 5, issue 5. May 2017.

\section{Polyetheretherketone (PEEK) as a medical and dental material. A literature review}

\subsection{Paper selection}

The titles identified in the literature searches were screened to determine whether the papers should be considered for full-text review. Full-text papers that met the inclusion criteria were selected for data abstraction.

\section{Literature search and results}

The literature search identified 40 references. Five were clinical reports
$[2,6,8,18,24]$ and 35 were papers on PEEK surface treatments [13-17] how the bioactivity of PEEK can be improved [1,21]; the characteristics of CFR-PEEK [3,7,19-20]; the biocompatibility of PEEK [5]; PEEK applications [4,8,10-11,30]; PEEK biofilm formation [22,31-34], PEEK as an abutment material and as an implant material $[12,23,25-29,35,40]$ and the use of CAD-CAM with PEEK [36-39].

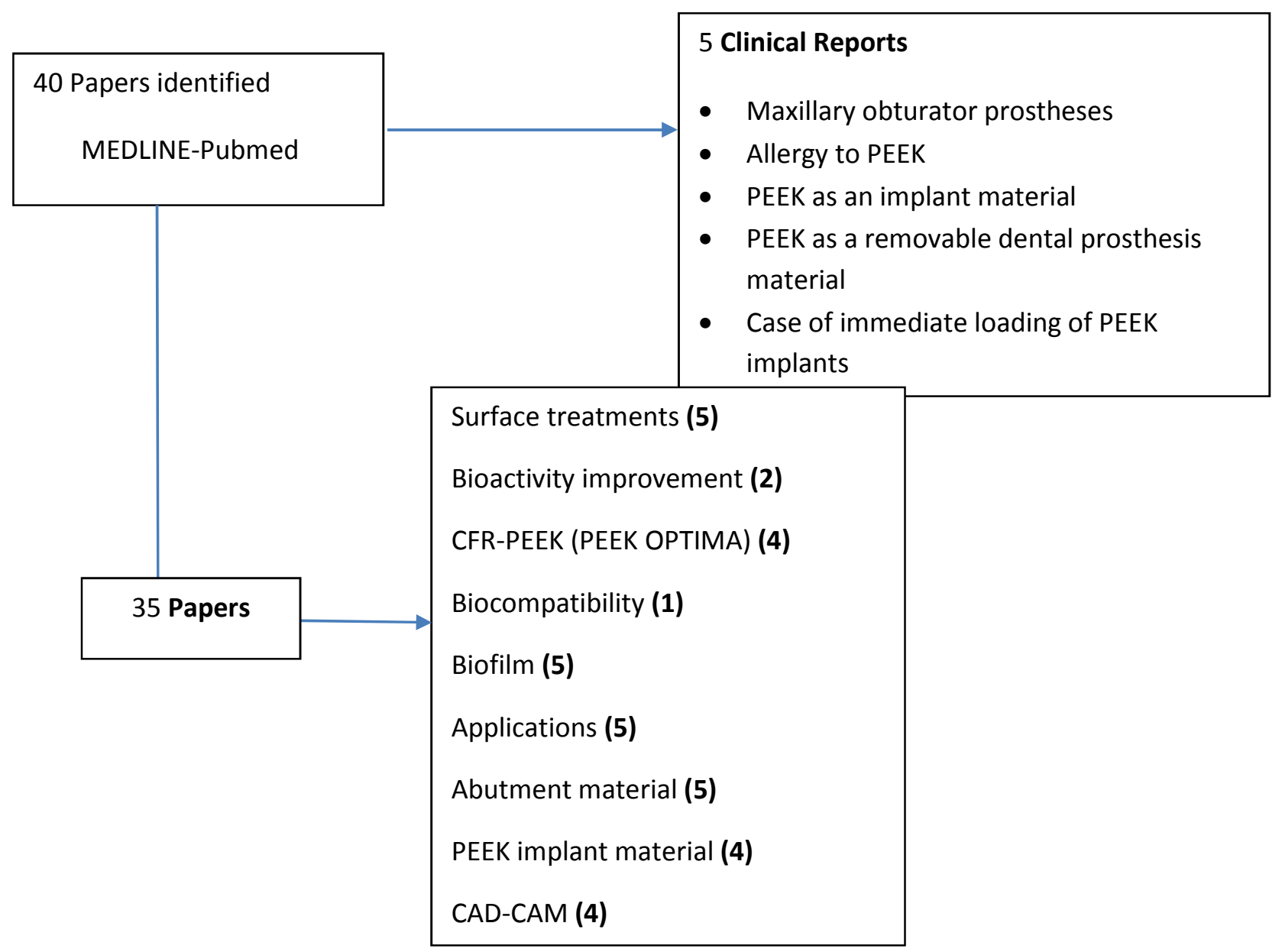

Figure 2: Literature search results 


\section{Polyetheretherketone (PEEK) as a medical and dental material. A literature review}

\subsection{Characteristics of the study}

The 35 papers and 5 clinical reports selected for this review were published between 2000 and 2015. Approximately $40 \%$ of the papers and case reports included in this review were published between 2014 and 2015.

\subsection{PEEK surface treatments}

Six papers [11,13-17] investigated the PEEK bonding techniques to dental composite resin materials. Sulfuric-acid etching can improve the bond strength of resin cements to PEEK surfaces [11,1617]. The use of hydrophobic adhesive containing methylmetacrylates was able to bond to PEEK and a composite resin [1415].

\subsection{BIC-Types of PEEK}

It has been reported that PEEK, compared with titanium, presented the lowest BIC [31-32]. To achieve good bioactivity, many modifications for pure PEEK have been proposed [1,3-4,9,14,17-22]. It has been suggested that the incorporation of nanosized particles, such as hydroxyfluorapatite (n-FHA), could inhibit bacterial adhesion and accelerate bacterial death, in order to reduce the risk of peri-implantitis [14-22]. Therefore, n-FHA appears to have a good potential for clinical applications as dental implants materials.

\subsection{Biofilm formation}

Three papers [30-32] concluded that biofilm formation on the surface of PEEK was equal to, or lower than on the surface of zirconia or titanium.

\subsection{Biocompatibility of PEEK}

Three papers reported the biocompatibility of PEEK. One of these [5] showed no evidence of cell damage caused by polyetheretherketone. A case report, [2] in contrast, described the clinical evidence of allergy to PEEK, in which the removal of the implant alleviated the patient's allergic symptoms. Another case report [18] described 3 cases of how a PEEK implant lead to poor osseointegration and subsequent infections and implant loss.

\subsection{Abutment material}

Abutment material plays an important role in the prevention of soft tissue recession. The most widely used materials used are: titanium, gold, base metals, zirconium or aluminum oxide ceramics. PEEK is currently used as a provisional abutment, because this material has been demonstrated to reduce stress shielding around the implant [23-25,27-28]. However, PEEK is not used as a definitive abutment material because its fracture resistance is lower than that of titanium [25,29-30].

\subsection{CAD-CAM}

PEEK is a good material for producing fixed and removable prostheses with CADCAM, because it is easier to mill, its mechanical properties are not adversely affected by the milling process, and its fracture resistance is higher than that of other materials [36-40].

\section{Discussion}

\subsection{Treatments in the surface of PEEK}

The clinical application of PEEK in fullcoverage monolithic restorations is limited by its low translucency and grayish color. 


\section{Polyetheretherketone (PEEK) as a medical and dental material. A literature review}

Therefore, additional resin composites for veneering are still necessary [13].

According to our research, the conventional protocol to treat the PEEK surface was abrasion, acid etching, laser treatment or plasma techniques. However, most of these techniques are difficult to apply under clinical settings in dentistry [14].

Schmidlin et al., in their study on the bonding techniques of PEEK to dental composite resin materials, described the different pre-treatments applied in PEEK surfaces, as explained in Table 1. The same authors used titanium as a control, and two bonding materials [14]:

- Universal composite resin cement RelyX Unicem (3M ESPE Minnesota, USA)

- Unfilled resin material (Heliobond, Ivoclar Vivadent, Schaan, Liechtenstein) and a fine hybrid composite resin material (Tetric, Vivadent).

\begin{tabular}{|c|l|l|l|l|}
\hline Group 1 & Group 2 & Group 3 & Group 4 & Group 5 \\
\hline & & & $\begin{array}{l}\text { Silica coating } \\
\text { with Rocatec } \\
\text { Pre for 10s and } \\
\text { subsequent }\end{array}$ \\
No treatment & $\begin{array}{l}\text { Acid etching } \\
\text { with sulfuric } \\
\text { acid 98\% for 1 } \\
\text { minute }\end{array}$ & $\begin{array}{l}\text { Sandblasting } \\
\text { with alumina } \\
\text { (particle size of } \\
50)\end{array}$ & $\begin{array}{l}\text { Sandblasting } \\
\text { with alumina } \\
\text { (particle size of } \\
110)\end{array}$ & $\begin{array}{l}\text { (3M ESPE) for } \\
\text { 12s. Application } \\
\text { of ESPE Sil and } \\
\text { air-drying for } \\
\text { 5min }\end{array}$ \\
\hline
\end{tabular}

Table 1: The different treatments applied on the PEEK surfaces [14]

Schmidlin et al. showed that a hydrophobic adhesive was able to bond to PEEK and a composite resin, whereas the universal composite resin cement did not appear to bond suitably to PEEK [14].

Kern et al. evaluated the bond strength to PEEK by using two different surface treatments and two conditioning methods. The first treatment was applied with airabrasion and Rocatec Pre (alumina particles) for $15 \mathrm{~s}$ and bonded with a resin (Luxatemp Fluorescence ${ }^{\circledR}$ ). Then, the PEEK was conditioned with different primers: Ecusit Composite Repair ${ }^{\circledR}$ or Luxatemp Glaze \& Bond ${ }^{\circledR}$ or Clearfil Ceramic Primer®. The second treatment was coated with silica (Rocatec-Plus) and silanated either with Espe Sil® or Clearfil Ceramic Primer. The results of their study showed that the use of methylmetacrylates containing resin varnish (Luxatemp Glaze $\&$ Bond) on air-abraded PEEK resulted in the highest median bond strength [15].

In a different study [11] the authors analyzed the bond strength of PEEK with two veneering resins after different applying conditioning methods. To evaluate the bond strength, they divided the PEEK specimens into 5 groups, and applied different treatments to each group. The results of Group B, in which the acid etching was applied with sulfuric acid, achieved the highest shear bond strength. Similar results were obtained by Sproesser et al. and Uhrenbacher et al. Both studies concluded that sulfuric-acid etching can improve the bond strength of resin cements to PEEK surfaces [16-17]. The application 
Medical Research Archives. Volume 5, issue 5. May 2017.

\section{Polyetheretherketone (PEEK) as a medical and dental material. A literature review}

of adhesive system such as Signum PEEK

strength of PEEK [17].

Bond or Visio.link increases the retention

\begin{tabular}{|c|c|c|c|c|}
\hline Group A & Group B & Group C & Group D & Group E \\
\hline $\begin{array}{l}\text { No } \\
\text { treatment }\end{array}$ & $\begin{array}{l}\text { Acid etching with } \\
98 \% \text { sulfuric acid for } \\
1 \mathrm{~min}\end{array}$ & $\begin{array}{lr}\text { Air-abrasion } & \text { for } \\
10 \mathrm{~s} \text { with } & 50 \\
\text { alumina }\end{array}$ & $\begin{array}{l}\text { Air-abrasion } \\
\begin{array}{l}10 \mathrm{~s} \text { for } \\
\text { alumina }\end{array}\end{array}$ & $\begin{array}{l}\text { Silica coating using } \\
\text { Rocatec System }\end{array}$ \\
\hline
\end{tabular}

Table 2: Conditioned PEEK surface groups

\subsection{Types of PEEK}

Many modifications to pure PEEK have been proposed in order to modify its mechanical and biological properties, and increase its bioactivity for dental and orthopedic applications. Some examples of these modifications are: CFR-PEEK (carbon-fiber-reinforced-PEEK); GFRPEEK (glass-fiber-reinforced PEEK); nano-TiO2/PEEK (PEEK combined with nano-particles of titanium dioxide), etc [18].

CFR-PEEK has historically been used in spinal cages, in fracture fixation and femoral prosthesis, in bone fixation screws, and cardiac and neurological leads. The material has also been used in orthopedic implants, and may be ideal for articulating implants. In the area of dentistry, CFRPEEK is used in the palatal section of maxillary obturator prostheses in patients with large oral-nasal defects [1,3-4,9,19]. The high fatigue resistance and toughness of CFR-PEEK could minimize the risk of implant fracture [20].

$\mathrm{n}-\mathrm{TiO}_{2}$, has been demonstrated to enhance the bioactivity of PEEK and improve osteoblast attachment and cells on n$\mathrm{TiO}_{2} / \mathrm{PEEK}$. This polymer is used in the fabrication of biomedical materials, especially dental implant orthopedic implants; therefore it could be a potential substitute for metal implant material [21].

The incorporation of nano-sized particles such as hydroxyfluorapatite (n-FHA) has been suggested to impart anti-microbial properties such as Streptococcus Mutans [14]. These particles could effectively prevent the proliferation and biofilm formation of bacteria.

The combination of nanofluorohydroxyapatite (n-FHA)-PEEK influences the structure of biofilms and could inhibit the bacteria adhesion and accelerate the bacterial death, thus reducing the risk of peri-implantitis [22].

\subsection{PEEK vs. Titanium}

Dental implants increase the quality of life for many partial or fully edentulous patients. The material of choice has been titanium and its alloys, which were introduced in the late 1960s by Branemark [23].

It has been demonstrated the use of titanium in implants is correlated with a range of drawbacks. These include hypersensitivity in the user, excessive stress on the implant-bone due to the gradient of difference in the elastic moduli, as well as certain esthetic problems. PEEK, which was first commercialized in April 
Medical Research Archives. Volume 5, issue 5. May 2017.

\section{Polyetheretherketone (PEEK) as a medical and dental material. A literature review}

1998 as a biomaterial for implants [23-25], has been proposed an alternative to titanium.

Regarding abutments, it has been reported that abutment material plays an important role in the prevention of soft tissue recession. The most widely used materials used are: titanium, gold, base metals, zirconium or aluminum oxide ceramics [26].

Linkevicius et al. in a study showed that titanium abutments did not possess better stability of peri-implant tissues than abutments made of gold, base metals, zirconium or aluminum oxide ceramics [26].

PEEK abutments have only recently been introduced into implant dentistry, and thanks to the fact these abutments reduce stress shielding between dental implants and the adjacent alveolar bone, they are also available as abutments for provisional implant restorations.

Tetelman et al., presenting 3 clinical cases using PEEK as a provisional abutment, showed that this polymer provides acceptable labial/buccal contours and support for the papillary tissues. Furthermore, the PEEK abutment is costeffective, easily modified to support a temporary prosthesis at the time of implant placement, and its color makes it easier to achieve a good provisional aesthetic result [27-28].

However, PEEK provisional abutments showed less fracture resistance than titanium abutments, therefore the use of PEEK abutments is recommended for placement of provisional fixed prosthesis for 1-3 months, in contrast to titanium temporary abutments, which are recommended longer periods in the mouth (6-12 months) [29-30].
Of the variety of materials used to process prosthetic abutments, titanium causes the most significant stress shielding to the adjacent bone. Prosthetic abutments made from this polymer can be expected to have improved torque efficiency and they are easier to remove in the event of fracture [25].

Neumann et al., comparing the fracture resistance of titanium abutment screws and PEEK and 30\% CFR-PEEK abutment screws, found that PEEK abutments screws and 30\% CFR-PEEK abutment screws had a lower fracture resistance than titanium abutment screws. According to their study, no differences were found between the fracture resistance of PEEK and 30\% CFRPEEK screws. Titanium had a higher fracture resistance compared with the polymers. The fracture location occurred at the neck of the screw [25].

In a different study, Neumann et al., compared the fracture strength of composite resin crowns fabricated directly over PEEK and titanium abutments. The authors also analyzed the location of the fracture (central incisor, lateral incisor, canine, first premolar) and the failure types (irreparable or reparable). The majority of the failures were irreparable. There were no significant differences between the abutments, except in the position of the maxillary central incisor, the temporary abutments fabricated with PEEK presented significant lower fracture strength [28].

Sarot et al. in a study using finite-element analysis (FEA) compared the stress distribution in the peri-implant bone in four different models of titanium abutment with titanium implant, CFR-PEEK abutment with titanium implant, titanium abutment with CFR-PEEK implant, and CFR-PEEK abutment with titanium implant. Their findings suggest that CFR-PEEK implants 


\section{Polyetheretherketone (PEEK) as a medical and dental material. A literature review}

presented a higher load concentration in the cervical area and at the cortical bone, whereas the titanium implants presented equivalent stress peaks in the cervical portion and a more homogenous load distribution throughout the whole implant body. The total demonstration analysis demonstrated a lower deformation of titanium implant and abutment, and a higher deformation in CFR-PEEK implant and abutment. The CFR-PEEK implant did not present any advantages in relation to the titanium implant regarding stress distribution to the peri-implant bone [3].

\begin{tabular}{|l|l|l|}
\hline Model & Implant & Abutment \\
\hline A & Titanium & Titanium \\
\hline B & Titanium & CFR-PEEK \\
\hline C & CFR-PEEK & Titanium \\
\hline D & CFR-PEEK & CFR-PEEK \\
\hline
\end{tabular}

Table 3: Characteristics of the different tested models [3]

The finding of Sarot et al. seems to indicate that a stronger reinforced PEEK dental implant could reduce stress peaks at the bone-implant interface, as a result of a reduced elastic deformation $[3,7]$.

Schwitalla et al. evaluated bone stresses and deformation in three materials for a platform-switched dental implantabutment. Type 1 consisted entirely of titanium; Type 2, of a powder-filled PEEK; and Type 3, of Endolign (an implantable carbon fiber reinforced with $60 \%$ endless carbon fibers). The results demonstrated that Endolign distributes the stresses similarly to titanium implant stresses [7].

Hahnel et al. compared bone-implantcontact (BIC) and shear strength of titanium-coated and uncoated CFR-PEEK implants. The titanium implants showed significantly higher BIC values [31].

In another study, implants of pure PEEK were inserted into a mandible next to implants made from titanium and zirconia and evaluated at 4 months; PEEK presented the lowest BIC [32].

PEEK it is slightly radiopaque, so is not easily visualized on conventional radiographs and the range of diameters and lengths available is rather restricted as compared to most current implant systems [32].

Regarding the biocompatibility of PEEK, very little is known about the long-term results and complications related to use of PEEK in oral surgery. Khonsari et al. described three cases of severe infectious complications from PEEK-based compounds. The compound used in the 3 cases was $\mathrm{PEEK}+\beta-\mathrm{TCP}+\mathrm{TiO}_{2}$. In the first case, the CT-scan showed alveolar bone loss around the implant and confirmed the absence of osseointegration of the PEEK implant [18].

According to the literature, to be used as a permanent material, it needs an increased/higher BIC, a lower stress 


\section{Polyetheretherketone (PEEK) as a medical and dental material. A literature review}

distribution on the peri-implant bone and an increased fracture resistance [31].

Nevertheless, PEEK implants have some advantages over titanium. Their color is a perfect match for the esthetic zone. In some cases, especially in thin soft tissue and also with gingival recession a small part of the titanium implant may become visible [31].

Regarding biofilm formation on the surface of implant abutment materials, Hahnel et al., evaluating the formation in titanium, zirconia, PEEK and PMMA [31], found that biofilm formation on the surface of PEEK is equal to or lower than the formation on the surfaces of zirconia or titanium. Similar results obtained by Volpe et al. [32] found no significant difference in the bacterial colonization between PEEK and titanium abutment. Hence, PEEK could be a viable alternative to titanium in the fabrication of abutments [30].

Nascimento et al. [33] in their study evaluating biofilm formation exclusively in titanium and zirconia concluded there were no significant differences between the two materials. Conversely, in other study, the same authors [34] concluded that there was a significant difference: titanium presented most bacteria and also showed a higher mean incidence of species than did zirconia.

The material used in the abutment portion of the implant was a crucial to the quality of the attachment that occurs between the mucosa and the implant. In a study comparing the soft and hard tissue responses to titanium and polymer abutments over a 3-month period, Koutouzis et al. observed the following parameters at the 2-week and 3-months: presence of visible plaque, probing depth, bleeding on probing, peri-implant mucosa height, and the width of buccal keratinized mucosa. Radiographic examinations taken after the surgery and at 3 months postsurgery (Figure 10), showed a significant difference in plaque accumulation between PEEK and titanium abutments at the 2week examination; however there was no significant difference at 3 months. During the 3 months, the two groups showed minimal marginal bone loss [35]. Table 4 summarizes the main features of titanium and PEEK. 
Polyetheretherketone (PEEK) as a medical and dental material. A literature review

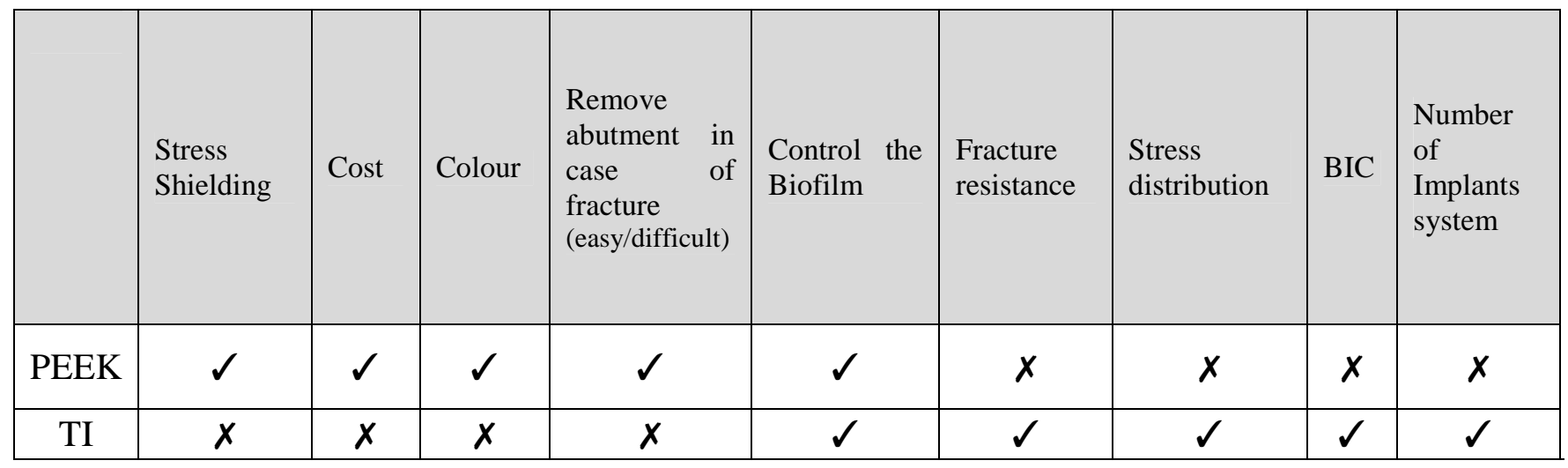

Table 4: Characteristics of titanium and PEEK.

\subsection{PEEK and CAD-CAM}

CAD-CAM (Computer-Aided-Designed Computer-Aided-Manufactured) is a design, fabrication and manufacturing process used for fixed restorative and prosthodontic treatment procedures, using biocompatible materials including alloys, ceramics and high-performance polymers. CAD-CAM also reduces chairside time and also produces good results [36].

PEEK is an attractive material for producing CAD-CAM fixed and removable prostheses, because it is easier to mill than titanium and it is also easy to polish. Milling with PEEK is highly recommended because the resulting non-allergenic prostheses are lighter than those made of other materials, such as $\mathrm{Co}-\mathrm{Cr}$ or titanium, and the milling process does not adversely affect the mechanical properties of the PEEK material [37-38].

It has been reported that the fracture resistance of the CAD-CAM milled PEEK fixed dentures is much higher than that of alumina, zirconia and lithium disilicate glass-ceramic [39-40].

\section{Conclusion}

The literature suggests that PEEK offers an alternative to titanium, especially in cases of orthopedics and trauma.

The properties of PEEK (its biocompatibility, color appearance, similar elastic modulus to the cortical bone 3-4 $\mathrm{GPa}$ ) make it an interesting material for dental implants, provisional abutments, prosthodontic applications, such as fixed and removable prostheses, and esthetic orthodontic wires.

Furthermore, polyetheretherketone it is an attractive material to produce fixed and removable prostheses with CAD-CAM.

Studies report the use of this polymer as a temporal abutment. Its lower fracture resistance, stress distribution that causes deformation around the implant and abutment, and its low BIC are likely the reasons preventing the use of PEEK as a permanent abutment or as an implant material. PEEK is used as a temporary abutment because PEEK abutments are less likely to resist masticatory forces than titanium abutments. Nevertheless in order to increase its BIC, PEEK requires improved its bioactivity. PEEK can be modified easily without affecting its 
Medical Research Archives. Volume 5, issue 5. May 2017.

\section{Polyetheretherketone (PEEK) as a medical and dental material. A literature review}

mechanical properties, by incorporation of other materials such as carbon fibers (18GPa), glass fibers, hydroxyapatite, etc.

Further studies and clinical trials should be conducted with a view to improving the qualities of PEEK to enable its uses as a permanent abutment material in dental implants. To this end, it is necessary to decrease the stress distribution around the bone, and increase the fracture resistance.

\section{Acknowledgements}

The authors are very grateful for the valuable contributions to this literature review and help from Mark Lodge and Andrea Solans. 
Medical Research Archives. Volume 5, issue 5. May 2017.

\section{Polyetheretherketone (PEEK) as a medical and dental material. A literature review}

\section{References}

1. Ma R, Tang T. Current strategies to improve the bioactivity of PEEK. Int $\mathbf{J}$ Mol Sci 2014;15(4): 5426-5445.

2. Maldonado-Naranjo AL, Healy AT, Kalfas IH. Polyetheretherketone (PEEK) intervertebral cage as a cause of chronic systemic allergy: a case report. Spine J 2015;15(7):1-3.

3. Sarot JR, Contar CM, Cruz AC, de Souza Magini R. Evaluation of the stress distribution in CFR-PEEK dental implants by the three-dimensional finite element method. J Mater Sci Mater Med 2010;21(7):2079-2085.

4. Kurtz SM, Devine JN. PEEK biomaterials in trauma, orthopedic, and spinal implants. Biomaterials 2007;28(32):4845-4869.

5. Katzer A, Marquardt H, Westendorf J, Wening JV, von Foerster G. Polyetheretherketone--cytotoxicity and mutagenicity in vitro. Biomaterials 2002;23(8):1749-1759.

6. Zoidis P, Papathanasiou I, Polyzois G. The use of a modified poly-ether-etherketone (PEEK) as an alternative framework material for removable dental prostheses. a clinical report. J Prosthodont 2016;25(7):580-584.

7. Schwitalla AD, Abou-Emara M, Spintig T, Lackmann J, Müller WD. Finite element analysis of the biomechanical effects of PEEK dental implants on the peri-implant bone. J Biomech 2015;48(1):1-7.

8. Schwitalla AD, Spintig T, Kallage I, Müller WD. Flexural behavior of PEEK materials for dental application. Dent Mater 2015;31(11):1377-1384.

9. Costa-Palau S, Torrents-Nicolàs J, Brufau de Barberà M, Cabratosa-Termes J. Use of polyetheretherketone in the fabrication of a maxillary obturator prosthesis: a clinical report. J Prosthet Dent 2014;112(3):680-682.

10. Maekawa M, Kanno Z, Wada T, Hongo $\mathrm{T}$, Doi $\mathrm{H}$, Hanawa $\mathrm{T}$, Ono $\mathrm{T}$, Uo $\mathrm{M}$. Mechanical properties of orthodontic wires made of super engineering plastic. Dent Mater J 2015;34(1):114-119.

11. Stawarczyk B, Beuer F, Wimmer T, Jahn D, Sener B, Roos M, Schmidlin PR. Polyetheretherketone-a suitable material for fixed dental prostheses? J Biomed Mater Res B Appl Biomater 2013;101(7):1209-1216.

12. Lee W, Koak J, Lim Y, Kim S, Kwon H, Kim M. Stress shielding and fatigue limits of poly-ether-ether-ketone dental implants. J Biomed Mater Res B Appl Biomater 2012;100(4):1044-1052.

13. Keul C, Liebermann A, Schmidlin PR, Roos M, Sener B, Stawarczyk B. Influence of PEEK surface modification on surface properties and bond strength to veneering resin composites. J Adhes Dent 2014;16(4):383-392.

14. Schmidlin PR, Stawarczyk B, Wieland M, Attin T, Hämmerle $\mathrm{CH}$, Fisher $\mathrm{J}$. Effect of different surface pre-treatments and luting materials on shear bond strength to PEEK. Dent Mater 2010;26(6):553-559.

15. Kern M, Lehmann F. Influence of Surface conditioning on bonding to 


\section{Polyetheretherketone (PEEK) as a medical and dental material. A literature review}

polyetheretherketon (PEEK). Dent Mater 2012;28(12):1280-1283.

16. Sproesser O, Schmidlin P, Uhrenbacher J, Roos M, Gernet W, Stawarczyk B. Effect of sulfuric acid etching of polyetheretherketone on the shear bond strength to resin cements. J Adhes Dent 2014;16(5):465-472.

17. Uhrenbacher J, Schmidlin P, Keul C, Eichberger M, Roos M, Gernet W, Stawarczyk B. The effect of surface modification on the retention strength of polyethrethrketone crowns adhesively bonded to dentin abutments. J Prosthet Dent 2014;112(6):1489-1497.

18. Khonsari RH, Berthier P, Rouillon T, Perrin JP, Corre P. Severe infectious complications after PEEK-derived implant placement: report of three cases. J Oral Maxillofac Surg Med Pathol 2014;26(4):477-482.

19. Li CS, Vannabouathong C, Sprague S, Bhandari $\mathrm{M}$. The use of carbon-fiberreinforced (CFR) PEEK material in orthopedic implants: a systematic review. Clin Med Insights Arthritis Musculoskelet Disord 2015;23(8):33-45.

20. Nakahara I, Takao M, Bandoh S, Bertollo N, Walsh WR, Sugano N. In vivo implant fixation of carbon fiberreinforced PEEK hip prostheses in an ovine model. J Orthop Res 2013;31(3):485-492.

21. Wu X, Liu X, Wei J, Ma J, Deng F, Wei S. Nano-TiO2/PEEK bioactive composite as a bone substitute material: in vitro and in vivo studies. Int $\mathrm{J}$ Nanomedicine 2012;7:1215-1225.

22. Wang L, Zhang H, Deng Y, Luo Z, Liu $X$, Wei S. Study of oral microbial adhesion and biofilm formation on the surface of nano-fluorohydroxyapatite/ polyetheretherketone composite. Zhonghua Kou Qiang Yi Xue Za Zhi. 2015;50(6):378-382.

23. Schwitalla A, Müller WD. PEEK Dental Implants: a review of the literature. J Oral Implantol 2013;39(6):743-749.

24. Marya K, Dua JS, Chawla S, Sonoo PR, Aggarwal A, Singh V. Polyetheretherketone (PEEK) Dental Implants: a case for immediate loading. Int J Oral Implantol Clin Res. 2011;2(2):97-103.

25. Neumann EA, Villar CC, França FM. Fracture resistance of abutment screws made of titanium, polyetheretherketone, and carbon fiber-reinforced polyetheretherketone. Braz Oral Res 2014;28(1):1-5.

26. Linkevicius T, Apse P. Influence of abutment material on stability of periimplant tissues: a systematic review. Int J Oral Maxillofac Implants 2008;23(3):449-456.

27. Tetelman ED, Babbush CA. A new transitional abutment for immediate aesthetics and Function. Implant Dent 2008;17(1):51-58.

28. Santing HJ, Meijer HJ, Raghoebar GM, Özcan M. Fracture strength and failure mode of maxillary implant-supported provisional single crowns: a comparison of composite resin crowns fabricated directly over PEEK abutments and solid titanium abutments. Clin Implant Dent Relat Res 2012;14(6):882-889.

29. Agustin-Panadero R, Serra-Pastor B, Roig-Vanaclocha A, Román-Rodriguez J, Fons-Font A. Mechanical behavior of 


\section{Polyetheretherketone (PEEK) as a medical and dental material. A literature review}

provisional implant prosthetic abutments. Med Oral Patol Oral Cir Bucal 2015;20(1):94-102.

30. Najeeb S, Zafar MS, Khurshid Z, Siddiqui F. Applications of polyetheretherketone (PEEK) in oral implantology and prosthodontics. J Prosthodont Res 2016;60(1):12-19

31. Hahnel S, Wieser A, Lang R, Rosentritt M. Biofilm formation on the surface of modern implant abutment materials. Clin Oral Implants Res 2015;26(11):12971301.

32. Volpe S, Verrocchi D, Andersson P, Gottlow J, Sennerby L. Comparison of early bacterial colonization of PEEK and titanium healing abutments using realtime PCR. Applied Osseoint Res 2008;6:54-56.

33. do Nascimento C, da Rocha Aguiar C, Pita MS, Pedrazzi V, de Albuquerque RF, Ribeiro RF. Oral biofilm formation on the titanium and zirconia substrates. Micros Res Tech 2013;76(2):126-132.

34. do Nascimento C, Pita MS, Fernandes FHNC, Pedrazzi V, de Albuquerque Junior RF, Ribeiro RF. Bacterial adhesion on the titanium and zirconia abutment surfaces. Clin Oral Implants Res 2014;25(3):337-343.

35. Koutouzis T, Richardson J, Lundgren T. Comparative soft and hard tissue responses to titanium and polymer healing abutments. J Oral Implantol 2011;37:174-182.
36. Tahmaseb A, De Clerck R, Wismeijer D. Computer-guided implant placement: 3D planning software, fixed intraoral reference points, and CAD/CAM technology. A case report. Int $\mathbf{J}$ Oral Maxillofac Implants 2009;24(3):541546.

37. Alt V, Hannig M, Wöstmann B, Balkenhol M. Fracture strength of temporary fixed partial dentures: CADCAM versus directly fabricated restorations. Dental Mater 2011;27(4):339-347.

38. Stawarczyk B, Ender A, Trottmann A, Özcan M, Fischer J, Hämmerle $\mathrm{CH}$. Load-bearing capacity of CAD-CAM milled polymeric three-unit fixed dental prostheses: effect of aging regimens. Clin Oral Investig 2012;16(6):16691677.

39. Beuer F, Steff B, Naumann M, Sorensen JA. Load-bearing capacity of all-ceramic three-unit fixed partial dentures with different computer-aided design (CAD)/ computer-aided manufacturing (CAM) fabricated framework materials. Eur $\mathbf{J}$ Oral Sci 2008;116(4):381-386.

40. Kolbeck C, Behr M, Rosentritt M, Handel G. Fracture force of tooth-toothand implant-tooth-supported all-ceramic fixed partial dentures using titanium vs. customized zirconia implant abutments. Clin Oral Implants Res 2008;19(10):1049-1053. 